\title{
Modulation of monosodium urate crystal-induced responses in neutrophils by the myeloid inhibitory C-type lectin-like receptor: potential therapeutic implications
}

Valérie Gagné ${ }^{1 \dagger}$, Louis Marois ${ }^{1+}$, Jean-Michel Levesque ${ }^{1}$, Hugo Galarneau', Mireille H Lahoud ${ }^{2}$, Irina Caminschi², Paul H Naccache', Philippe Tessier ${ }^{1}$ and Maria JG Fernandes ${ }^{1 *}$

\begin{abstract}
Introduction: Monosodium urate crystals (MSU), the etiological agent of gout, are one of the most potent proinflammatory stimuli for neutrophils. The modulation of MSU-induced neutrophil activation by inhibitory receptors remains poorly characterized. The expression of the myeloid inhibitory C-type lectin-like receptor (MICL) in neutrophils is downregulated by several proinflammatory stimuli, suggestive of a role for this receptor in neutrophil function. We thus investigated the potential role of MICL in MSU-induced neutrophil activation.

Methods: The expression of MICL was monitored in human neutrophils by flow cytometry and Western blot analysis after stimulation with MSU. Protein tyrosine phosphorylation was also assessed by Western blot analysis and the production of IL-1 and IL-8 by enzyme-linked immunosorbent assay. Changes in the concentration of cytoplasmic free calcium were monitored with the Fura-2-acetoxymethyl ester calcium indicator. MICL expression was modulated with an anti-MICL antibody in neutrophils and siRNA in the PLB-985 neutrophil-like cell line.

Results: MSU induced the downregulation of MICL expression in neutrophils. A diminution in the expression of $\mathrm{MICL}$ induced by antibody cross-linking or siRNA enhanced the MSU-dependent increase in cytoplasmic calcium levels, protein tyrosine phosphorylation and IL-8 but not IL-1 production. Pretreatment of neutrophils with colchicine inhibited the MSU-induced downregulation of MICL expression.

Conclusions: Our findings strongly suggest that MICL acts as an inhibitory receptor in human neutrophils since the downregulation of MICL expression enhances MSU-induced neutrophil activation. Since MSU downregulates the expression of MICL, MICL may play a pathogenic role in gout by enhancing neutrophil effector functions. In support of this notion, colchicine counteracts the MSU-induced loss of MICL expression. Our findings thus also provide further insight into the potential molecular mechanisms behind the anti-inflammatory properties of this drug.
\end{abstract}

Keywords: Cytokine production, out, Immunoreceptor tyrosine-based inhibitory motif, Monosodium urate crystals, Neutrophil, Signaling

\footnotetext{
* Correspondence: maria.fernandes@crchul.ulaval.ca

+ Contributed equally

${ }^{1}$ Department of Microbiology, Infectious Diseases, and Immunology, Faculty

of Medicine, Laval University, Centre for Research in Immunology and Rheumatology, Research Centre CHUQ-CHUL, Bloc T1-49, 2705 boulevard

Laurier, Quebec, QC, G1V 4G2, Canada

Full list of author information is available at the end of the article
} 


\section{Introduction}

Gout is one of the most painful types of arthritis, and its prevalence is on the rise worldwide [1,2]. The inflammatory reaction typical of an acute gout attack is initiated by the crystallized form of a by-product of purine metabolism, monosodium urate crystals (MSU). A gout attack can be viewed in three phases: the initiation phase, the effector phase and the subsequent resolution phase. According to the current understanding of the pathogenesis of acute gout, MSU activate resident articular cells (for example, macrophages) during the initiation phase, most commonly in the metatarsophalangeal joint [3]. The activation of resident cells by MSU induces the synthesis of several inflammatory mediators, including active interleukin $1 \beta$ (IL-1 $\beta$ ), a cytokine that plays a pivotal role in the pathogenesis of gout, implicating nucleotide-binding oligomerization domain-like receptor containing pyrin domain 3 (NLRP3) inflammasome in this inflammatory disorder. IL- $1 \beta$ contributes to the initiation and perpetuation of the effector phase by virtue of its ability to stimulate endothelial cells of the vasculature to express potent chemokines (for example, IL-8) and adhesion molecules responsible for the massive recruitment of neutrophils to the joint.

The recruitment of a large number of neutrophils to the affected joint during the effector phase is the pathological hallmark of gouty arthritis [4]. The presence of activated phagocytes in the joint is one of the main causes of tissue destruction and pain in gout. When activated by MSU, neutrophils release a panoply of inflammatory molecules, including cytokines (for example, IL-1 $\beta$, IL-8, S100) and degradative enzymes, that perpetuate the inflammatory reaction as well as oxygen radicals that cause damage to the surrounding tissues (recently reviewed by Popa-Nita and Naccache [4]). At the molecular level, the signaling molecules driving MSU-induced neutrophil responses are just beginning to be identified. They include activated Src family kinases (for example, Lyn), Syk, protein kinase C (PKC), phosphoinositide 3-kinase (PI3K) and Tec [4]. Since the activation of Src kinases is an early signaling event, the majority of MSU-induced effector functions depend on these kinases.

Animal studies and clinical observations underscore the pivotal role of the neutrophil in gout. A significant decrease in MSU-induced inflammation was reported in neutropenic mice. Moreover, medications used to treat gout, such as colchicine, downregulate MSU-induced neutrophil effector functions [4]. It is thus of interest to characterize molecular mechanisms that regulate MSUinduced neutrophil activation.

Leukocyte activation is regulated in part by phosphatases that block early signaling events of activating receptors when recruited to the plasma membrane.
Phosphatase recruitment occurs via immunoreceptor tyrosine-based inhibitory motifs (ITIMs) located in the cytoplasmic portion of inhibitory receptors expressed on the surface of leukocytes [5]. Inhibitory receptors can be classified into two main groups on the basis of their structure, namely, the immunoglobulin or the C-type lectin superfamily. Proteins of the latter contain at least one C-type lectin-like domain (CTLD). Myeloid inhibitory C-type lectin receptors are poorly characterized in comparison to their counterparts in natural killer cells (recently reviewed by Pyz et al. [6]). Findings from the few myeloid inhibitory receptors studied suggest, however, that these proteins are able to suppress several phagocyte effector functions, including phagocytosis, migration and cytokine production [7].

The myeloid inhibitory C-type lectin-like receptor (MICL) is a type II transmembrane protein comprising one CTLD in its extracellular domain and an ITIM in its cytoplasmic domain [8-12]. It is expressed by monocytes, macrophages, neutrophils, myeloid and plasmacytoid dendritic cells. The natural ligands of human MICL remain to be identified. Although unequivocal evidence of a negative regulatory function of MICL is still lacking in the published literature, the majority of the evidence suggests that MICL does indeed have inhibitory activity. The recruitment of the SH2-containing tyrosine phosphatases SHP-1 and SHP-2 to the ITIM of MICL was observed in a macrophage cell line [8]. Moreover, in response to a variety of Toll-like receptor (TLR) ligands, the cell surface expression of MICL diminishes in human monocytes and macrophages, suggestive of a negative regulatory role for this receptor [9]. In support of this hypothesis, the cell surface expression of MICL was shown to be diminished in neutrophils recruited to a site of inflammation using an abrasion model of the skin in human volunteers [9]. The antibody-induced internalization of MICL in monocytederived dendritic cells, however, showed that the loss of cell surface MICL can either positively or negatively regulate cytokine production. The internalization of MICL prior to stimulation with lipopolysaccharide (LPS) suppresses the production of IL-12p40 and IL-12p70 [10]. In contrast, the internalization of MICL prior to stimulation with the CD40 ligand enhances the production of tumor necrosis factor $\alpha$ (TNF- $\alpha$ ), IL-12p40, IL-12p70, IL-6 and IL-10 [10]. A role for MICL in antibody responses has also been reported. Targeting antigens to MICL can induce antibody responses [13].

Since MICL regulates the synthesis of cytokines in dendritic cells and its expression is modulated by proinflammatory stimuli, the objective of this study was to investigate the role of MICL in MSU-induced activation of neutrophils and to determine whether MSU modulate MICL expression. Herein we report for the first time that MSU diminish MICL expression in human neutrophils. 
A decrease in MICL expression in neutrophils selectively enhances MSU-induced cytokine release by neutrophils and also potentiates early signaling events. We also provide direct evidence that colchicine inhibits the MSUinduced loss of cell surface MICL, suggesting that the regulation of MICL expression may be a new mechanism through which this drug dampens inflammation.

\section{Methods}

\section{Antibodies and chemicals}

Two different antibodies against MICL were used in this study. Monoclonal antibodies 50C1 [13] and HB3 which was kindly provided by Dr G Brown [8] recognize extracellular epitopes of MICL. FITC-conjugated $F\left(a b^{\prime}\right)_{2}$ fragment goat anti-mouse IgG antibody (Fc fragment-specific, catalog no. 115-096-071) was purchased from Jackson ImmunoResearch Laboratories (West Grove, PA, USA). Horseradish peroxidase-labeled sheep anti-mouse immunoglobulins (IgGs) (no. NXA931) were obtained from GE Healthcare (Uppsala, Sweden). The antiphosphotyrosine (clone 4G10, no. 05-321) and the anti-p85 (no. 06-195) antibodies were purchased from Upstate Biotechnology (Lake Placid, NY, USA). Monoclonal anti-flotillin-1 antibody (no. 610820) was purchased from BD Transduction Laboratories (Mississauga, ON, Canada). The mouse IgG2a isotype antibody (no. 0572) was purchased from Beckman Coulter (Mississauga, ON, Canada). Anti-CD11b antibody (OKM1, no. 88012702) was purchased from Sigma-Aldrich Canada (Oakville, ON, Canada), and the anti-FPRL1 antibody was obtained from R\&D Systems (Minneapolis, MN, USA). Sodium orthovanadate $\left(\mathrm{Na}_{3} \mathrm{VO}_{4}\right), \mathrm{N}^{6}, 2^{\prime}$-O-dibutyryladenosine 3',5'-cyclic monophosphate sodium salt (dibutyryl cyclic adenosine monophosphate (dibutyryl cAMP)), colchicine and Dextran T500 were obtained from Sigma-Aldrich Canada. 3-[(3Cholamidopropyl)dimethylammonio]propanesulfonic acid (CHAPS), aprotinin and leupeptin were purchased from Roche Applied Science (Laval, QC, Canada). The Western Lightning Chemiluminescence Plus ECL kit was obtained from PerkinElmer (Boston, MA, USA). Ficoll-Paque and 4-(2-hydroxyethyl)-1-piperazineethanesulfonic acid (HEPES) were obtained from Wisent (St-Bruno, QC, Canada). Protein A Sepharose was purchased from GE Healthcare. Gelatin was obtained from Fisher Scientific (Nepean, ON, Canada). Fura-2-acetoxymethyl ester (Fura2AM) was obtained from Invitrogen (Burlington, ON, Canada), and the triclinic MSU crystals were synthesized and characterized as previously described by Naccache $e t$ al. [14]. Endotoxin contamination was ruled out by Limulus amebocyte lysate assay. siGENOME SMARTpool MICL (no. D-021369-01) and siGENOME nontargeting small interfering RNA (siRNA) pool 1 (negative control, no. D-001206-13-05) were purchased from Dharmacon Inc (Lafayette, CO, USA).

\section{Cells}

The Institutional Review Board of Laval University (Quebec, QC, Canada) approved the study, and volunteers signed a consent form. Neutrophils were collected from healthy adult volunteers and isolated as previously described [15]. They were resuspended in $\mathrm{Mg}^{2+}$-free Hanks' balanced salt solution (HBSS) containing $1.6 \mathrm{mM}$ $\mathrm{CaCl}_{2}$. The myeloid cell line PLB-985 was obtained from the German Collection of Microorganisms and Cell Cultures (DSMZ; Braunschweig, Germany) and grown in RPMI 1640 medium containing 10\% decomplemented fetal bovine serum (FBS), $10 \mathrm{mM}$ HEPES, $1 \mathrm{mM} \mathrm{Na}^{+}$pyruvate at $37^{\circ} \mathrm{C}$ in a $5 \% \mathrm{CO}_{2}$ humidified atmosphere. The cells were maintained in culture for 12 passages before new batches were thawed. To induce differentiation to a neutrophil-like phenotype, PLB-985 cells were cultured in medium supplemented with $0.3 \mathrm{mM}$ dibutyryl cAMP for 3 days prior to each experiment.

\section{Transfection of dibutyryl cAMP-differentiated PLB-985 cells}

One day following the initiation of differentiation with $0.3 \mathrm{mM}$ dibutyryl cAMP, PLB-985 cells were transiently transfected using a nucleofection system obtained from Amaxa Biosystems (Cologne, Germany). Briefly, $2 \times 10^{6}$ cells were centrifuged and resuspended in $100 \mu \mathrm{l}$ of nucleofection buffer (25 mM HEPES, pH 7.4, $120 \mathrm{mM}$ $\mathrm{KCl}, 2 \mathrm{mM} \mathrm{MgCl} 2,10 \mathrm{mM} \mathrm{K} \mathrm{HPO}_{4}, 5 \mathrm{mM}$ L-cysteine) containing $3 \mu \mathrm{g}$ of MICL-specific siRNA (siMICL) or negative control siRNA (siCtrl). The samples were transferred into an electroporation cuvette, and transfections were performed using the program setting U-002. After nucleofection, cells were immediately transferred into prewarmed RPMI 1640 complete medium containing $0.3 \mathrm{mM}$ dibutyryl cAMP, 10\% FBS, 10 mM HEPES, $1 \mathrm{mM} \mathrm{Na}^{+}$pyruvate and maintained at $37^{\circ} \mathrm{C}$ in a $5 \%$ $\mathrm{CO}_{2}$ humidified atmosphere. Two days after nucleofection, cells were harvested and resuspended in $\mathrm{Mg}^{2+}$-free HBSS containing $1.6 \mathrm{mM} \mathrm{CaCl}_{2}$ for analysis.

\section{Flow cytometry analysis}

To monitor the plasma membrane expression of MICL on neutrophils stimulated with different agonists, neutrophils were transferred into tubes cooled in an ice bath to terminate the stimulations, then centrifuged at $400 \times g$ for $2 \mathrm{~min}$ at $4^{\circ} \mathrm{C}$. The cell pellets were then resuspended in buffer with $50 \mathrm{C} 1(1 \mu \mathrm{g} / \mathrm{ml})$ or the IgG2a isotype control antibody and incubated for $30 \mathrm{~min}$ on ice, washed, and centrifuged, and the resuspended cell pellets were incubated for a further $30 \mathrm{~min}$ on ice with FITC-labeled goat antimouse Fc $\gamma$-specific IgG (diluted 1:100 in HBSS/bovine serum albumin (HBSS/BSA) solution). Cells were then washed twice in HBSS/BSA and analyzed by flow cytometry using a FACSCanto II flow cytometer obtained from 
BD Biosciences (San Jose, CA, USA). To monitor the antibody-induced internalization of cell surface MICL, freshly isolated neutrophils were incubated with $50 \mathrm{C} 1$ antibody $(1 \mu \mathrm{g} / \mathrm{ml})$ or IgG2a isotype antibodies for the indicated times at $37^{\circ} \mathrm{C}$ and then washed, and the resuspended cell pellets were incubated for a further $30 \mathrm{~min}$ on ice with FITC-labeled goat antimouse Fc $\gamma$-specific IgG (diluted 1:100 in HBSS/BSA solution). In some experiments, neutrophils were treated with $10 \mu \mathrm{M}$ colchicine or diluent (dimethyl sulfoxide (DMSO)) for $30 \mathrm{~min}$ at $37^{\circ} \mathrm{C}$ and centrifuged to wash away the drug prior to stimulation with $1 \mathrm{mg} / \mathrm{ml} \mathrm{MSU}$ for $20 \mathrm{~min}$ at $37^{\circ} \mathrm{C}$.

\section{Trichloroacetic acid protein precipitation}

Human neutrophils $\left(20 \times 10^{6}\right.$ cells $\left./ \mathrm{ml}\right)$ were stimulated with MSU crystals $(1 \mu \mathrm{g} / \mathrm{ml})$ at $37^{\circ} \mathrm{C}$ and quickly centrifuged, then supernatants were precipitated with $15 \%$ trichloroacetic acid for $30 \mathrm{~min}$ at $4^{\circ} \mathrm{C}$. Samples were then centrifuged at $16,000 \times \mathrm{g}$ for $5 \mathrm{~min}$ and washed three times with acetone. Pellets were dried at $95^{\circ} \mathrm{C}$ for $2 \mathrm{~min}$ and resuspended in modified Laemmli buffer.

\section{Enzyme-linked immunosorbent assay}

The assessment of the extracellular IL-8 was performed using commercially available enzyme-linked immunosorbent assay (ELISA) kits (human IL-8 cytoset, no. CHC1303) from Invitrogen. All samples were measured in duplicate. Briefly, dibutyryl cAMP-differentiated PLB985 cells were stimulated for $3 \mathrm{~h}$ at $37^{\circ} \mathrm{C}$ with $1 \mathrm{mg} / \mathrm{ml}$ MSU crystals in RPMI 1640 and centrifuged $(16,000 \times g$ for $5 \mathrm{~min}$ ), then the supernatants were harvested and filtered. Extracellular IL-8 was quantified using commercially available ELISA kits (BD Biosciences). All samples were measured in triplicate. For the quantitation of extracellular IL- $1 \beta$, neutrophils primed with TNF- $\alpha$ or incubated in buffer were stimulated for $8 \mathrm{~h}$ with MSU at $37^{\circ} \mathrm{C}$, and IL- $1 \beta$ was quantified in the cell-free supernatant using a commercially available ELISA kit obtained from eBioscience (catalog no. 88-7010-22; San Diego, CA, USA). All samples were measured in duplicate. To determine the effect of colchicine on the MSUinduced production of IL-8, neutrophils were treated with $10 \mu \mathrm{M}$ colchicine or diluent (DMSO) for $30 \mathrm{~min}$ at $37^{\circ} \mathrm{C}$ prior to adding MSU $(1 \mathrm{mg} / \mathrm{ml})$ or buffer to the neutrophil-colchicine mixture and incubating it for a further $3 \mathrm{~h}$ at $37^{\circ} \mathrm{C}$. It is of note that the effect of colchicine on neutrophils is reversible (data not shown). For colchicine to be effective, it should not be removed from the neutrophil suspension for the duration of the experiment for assays longer than $20 \mathrm{~min}$.

\section{Electrophoresis and immunoblotting}

For Western blot analysis, cell suspensions were transferred directly into the same volume of $2 \times$ boiling modified Laemmli sample buffer $(1 \times$ buffer: $62.5 \mathrm{mM}$ Tris. $\mathrm{HCl}$ (pH 6.8), 4\% (wt/vol) sodium dodecyl sulfate (SDS), $5 \%$ (vol/vol) $\beta$-mercaptoethanol, $8.5 \%$ (vol/vol) glycerol, $2.5 \mathrm{mM}$ orthovanadate, $10 \mu \mathrm{g} / \mathrm{ml}$ leupeptin, $10 \mu \mathrm{g} / \mathrm{ml}$ aprotinin and $0.025 \%$ bromophenol blue) to terminate cell activation with MSU, then boiled for 7 min. Proteins were separated by SDS-PAGE on 10\% acrylamide gels under nonreducing conditions and transferred to polyvinylidene fluoride (PVDF) membranes. Blocking agents and antibodies were diluted in a Tris-buffered saline Tween 20 (TBST) solution $(25 \mathrm{mM}$ Tris $\cdot \mathrm{HCl}, \mathrm{pH} 7.8,190 \mathrm{mM} \mathrm{NaCl}, 0.15 \% \mathrm{vol} / \mathrm{vol}$ Tween 20). PVDF membranes were incubated in blocking solution (5\% wt/vol dried milk in TBST) prior to immunoblotting with the anti-MICL antibody (HB3 antibody) or anti-flotillin-1 antibody. Gelatin solution ( $2 \% \mathrm{wt} / \mathrm{vol})$ was used as a blocking solution prior to immunoblotting with the antiphosphotyrosine (4G10) antibody. AntiMICL and anti-flotillin antibodies were diluted 1:1,000 and antiphosphotyrosine antibodies was diluted 1:2,000. Horseradish peroxidase-labeled sheep antimouse IgG was diluted 1:20,000 in TBST solution. Chemiluminescence reagents were used to detect antibodies with a maximal exposure time of $5 \mathrm{~min}$. All the immunoblots presented were controlled for equal protein loading with an anti-p85 of PI3K antibody.

\section{Calcium mobilization}

Neutrophils $\left(1 \times 10^{7}\right.$ cells $\left./ \mathrm{ml}\right)$ were incubated for $30 \mathrm{~min}$ at $37^{\circ} \mathrm{C}$ with $1 \mu \mathrm{M}$ Fura-2AM, washed once in HBSS, resuspended to a concentration of $5 \times 10^{6} \mathrm{cells} / \mathrm{ml}$ and transferred to a temperature-controlled $\left(37^{\circ} \mathrm{C}\right)$ cuvette compartment of a spectrofluorometer (SLM 8000; SLM Instruments, Urbana, IL, USA). Cell-associated fluorescence was monitored at an excitation wavelength of $340 \mathrm{~nm}$ and an emission wavelength of $510 \mathrm{~nm}$. The internal calcium concentrations were calculated as described by Grynkiewicz et al. [16].

\section{Statistical analysis}

Statistical analyses were performed using a two-tailed Student's paired $t$-test on the raw data with GraphPad Prism 4 software (GraphPad Software, La Jolla, CA, USA). Significance was considered to be attained at a value of $P<0.05$.

\section{Results}

\section{Monosodium urate crystals reduce myeloid inhibitory}

\section{C-type lectin-like receptor expression in human neutrophils}

The modulation of the cell surface expression of MICL by a variety of TLR agonists in human monocytes, macrophages and monocyte-derived dendritic cells, as well as mouse neutrophils, prompted us to determine whether MICL expression is downregulated by proinflammatory 
stimuli, in this case, MSU. The cell surface expression of MICL was monitored by flow cytometry in human neutrophils stimulated for up to $20 \mathrm{~min}$ with $1 \mathrm{mg} / \mathrm{ml} \mathrm{MSU}$ (Figure 1A). After $1 \mathrm{~min}$ of stimulation, the level of expression of cell surface MICL remained unchanged. In contrast, a significant reduction in the expression of MICL was observed after $20 \mathrm{~min}$ of stimulation with MSU. For comparative purposes, the modulation of the cell surface expression of MICL by soluble agonists was also examined. None of the agonists tested, TNF- $\alpha$, granulocytemacrophage colony-stimulating factor, granulocyte colony-stimulating factor, platelet-activating factor, the TLR4 ligand LPS and the TLR1 and TLR2 ligand Pam3CSK4 ( $N$-palmitoyl-S-(2,3-bis(palmitoyloxy)-(2RS)-propyl)-( $R$ )Cys-(S)-Ser-(S)-Lys trihydrochloride

data not shown), modulated MICL plasma membrane expression. Similarly, we detected no change in the surface expression of MICL in response to the particulate stimulus, nonopsonized zymosan (Figure 1B). MSU is thus the only stimulus tested that can directly induce the internalization of cell surface MICL. To determine whether the internalization of MICL observed with the above stimuli could be induced with the anti-MICL antibody (clone 50C1), neutrophils were incubated with $50 \mathrm{C} 1$ antibody, and internalization was assessed by flow cytometry with a fluorochrome-conjugated secondary antibody as described in the Methods section. We show that $50 \mathrm{C} 1 \mathrm{can}$ induce the internalization of cell surface MICL in human neutrophils (Figure 1C).

We then asked whether the change in cell surface MICL was accompanied by the degradation of the receptor. To test this hypothesis, an aliquot of the human neutrophil suspension (cell pellet and supernatant) stimulated with MSU was lysed and assessed by Western blot analysis with an anti-MICL antibody. A significant decrease in the amount of total MICL was observed (Figures $2 \mathrm{~A}$ and $2 \mathrm{~B}$ ). Since the lysate analyzed represents extracellular and intracellular MICL, these results indicate that the fate of
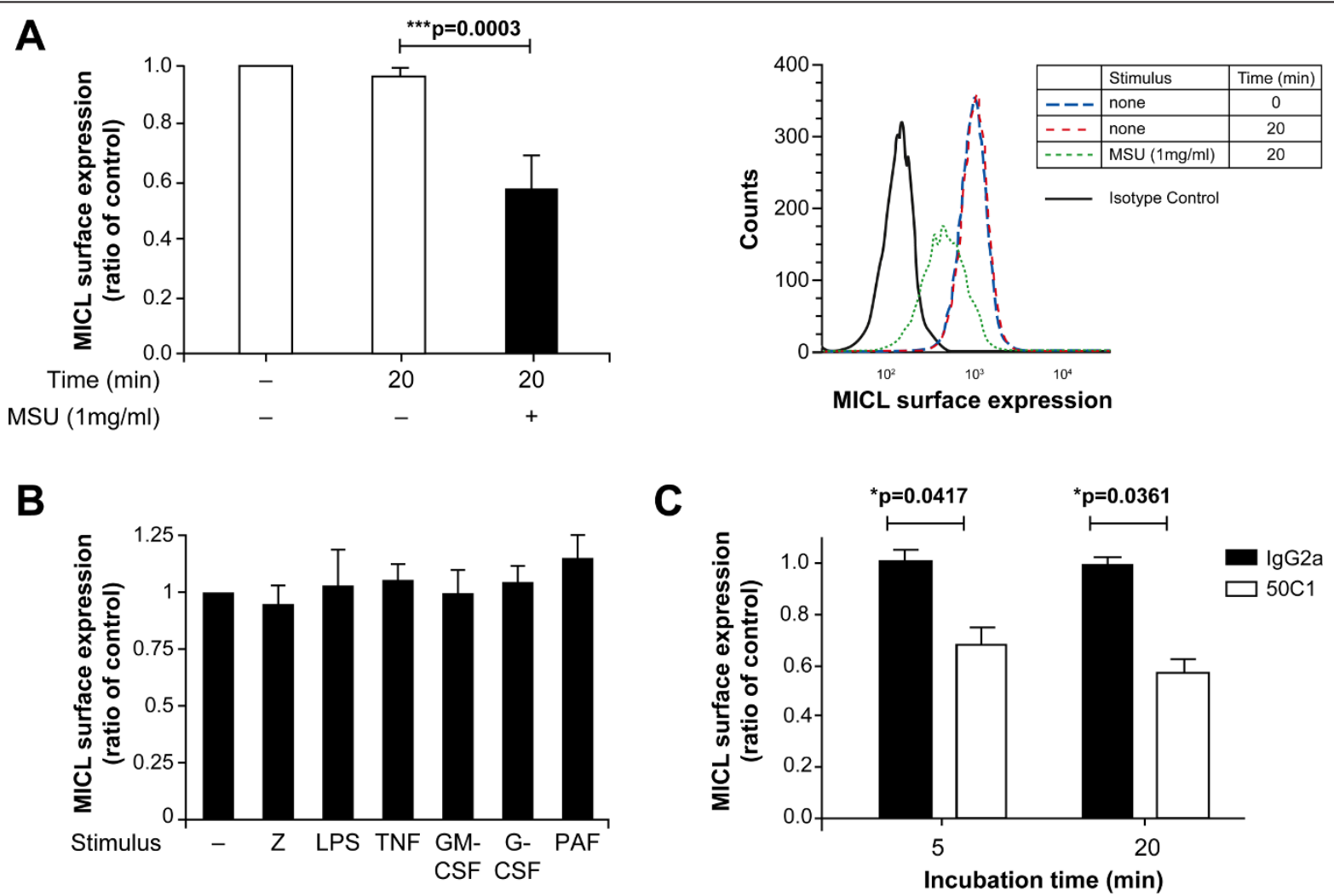

Figure 1 Surface myeloid inhibitory C-type lectin-like receptor (MICL) expression is significantly decreased upon activation of human neutrophils with monosodium urate crystals (MSU). The plasma membrane expression of MICL was examined by flow cytometry on freshly isolated neutrophils $\left(10 \times 10^{6} \mathrm{cells} / \mathrm{ml}\right)$ after incubation at $37^{\circ} \mathrm{C}$ with $(\mathbf{A}) \mathrm{MSU}(1 \mathrm{mg} / \mathrm{ml})$ for $20 \mathrm{~min}$, (B) nonopsonized zymosan $(z)($ ratio $=10$ z/cell), lipopolysaccharide (LPS) $(22.5 \mathrm{ng} / \mathrm{ml}$ in $1 \times$ Hanks' balanced salt solution containing $5 \%$ decomplemented fetal bovine serum), tumor necrosis factor $\alpha$ (TNF- $\alpha ; 100 \mathrm{U} / \mathrm{ml})$, granulocyte-macrophage colony-stimulating factor $(80 \mathrm{nM})$, granulocyte colony-stimulating factor (50 $\mathrm{ng} / \mathrm{ml}$ ) or platelet-activating factor $\left(10^{-6} \mathrm{M}\right)$ for $15 \mathrm{~min}$ or $(\mathrm{C})$ the $50 \mathrm{C} 1$ antibody $(1 \mathrm{\mu g} / \mathrm{ml})$ or lgG2a isotype control antibody for $5 \mathrm{~min}$ or $20 \mathrm{~min}$ as described in Methods. MICL expression was compared to the control. The raw flow cytometry data in (A) is shown in the right panel. These graphs are compilations from four independent experiments. 


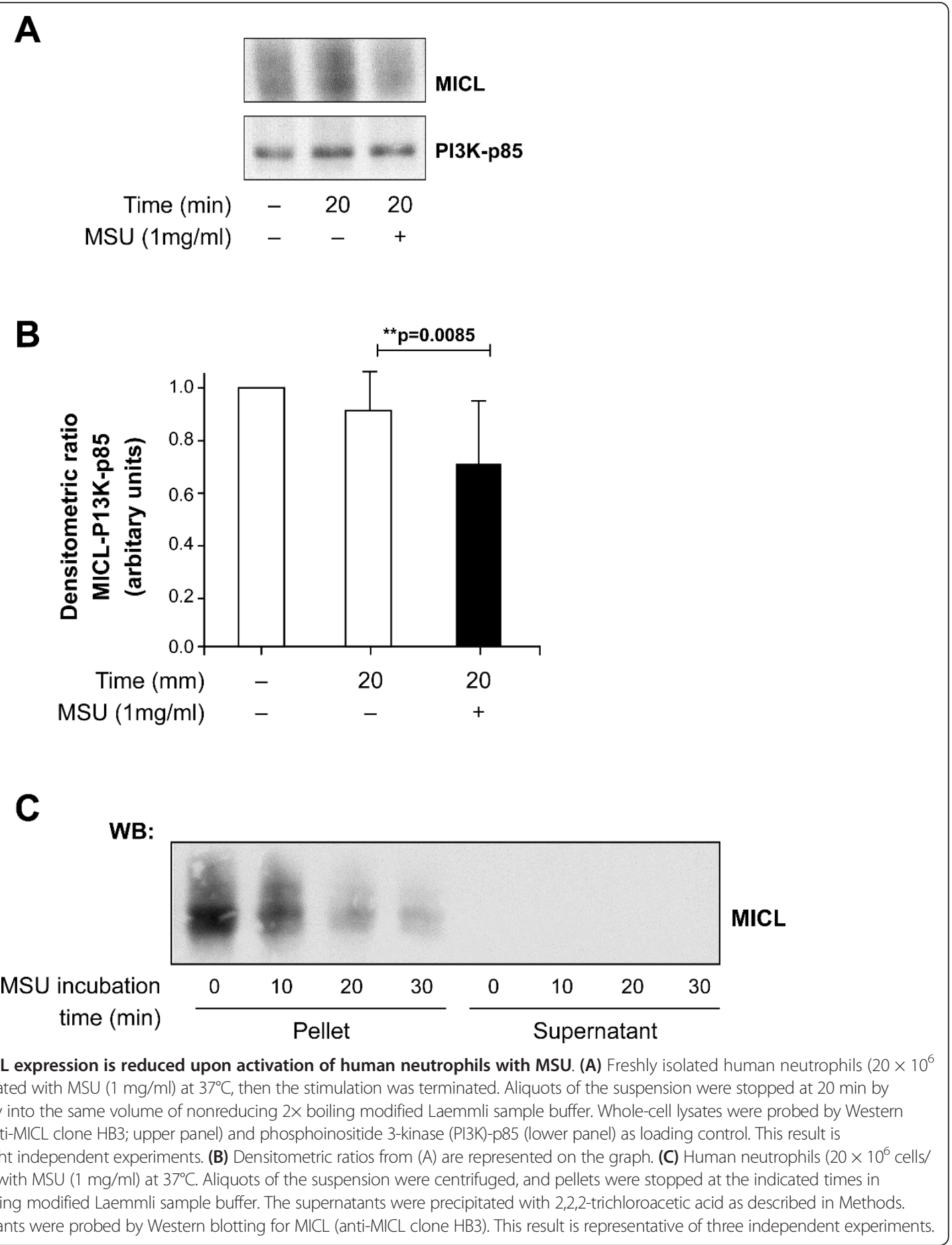

the MICL receptor after its internalization is its degradation. Analysis of the cell pellet and supernatant separately supported this interpretation of our observations because MICL was not detectable in the supernatant of MSU-activated neutrophils (Figure 2C). Stimulation of neutrophils with MSU thus induces not only the downregulation of the expression of cell surface MICL but also its degradation.
Myeloid inhibitory C-type lectin-like receptor negatively regulates the production of IL-8 by monosodium urate crystal-activated human neutrophils

To determine the functional significance of the downregulation of MICL expression by MSU, we next examined the effect of the silencing of MICL expression on MSU-induced cytokine production because MICL is 
known to modulate the synthesis of cytokines by monocyte-derived dendritic cells. The refractory nature of neutrophils to transfection prompted us to use PLB-985 cells that acquire a neutrophil-like phenotype upon differentiation with dibutyryl cAMP [17-19]. Upon differentiation, PLB-985 cells increase the cell surface expression of Mac-1 (Figure 3A and [20]) and FLPR1 (Figure 3A). Moreover, both published results and our unpublished observations reveal that the response of this cell line to MSU crystals is similar to that of human neutrophils [19].

To verify that the expression of MICL can be knocked down in PLB-985 cells, the cells were transfected with control siRNA or MICL siRNA, and the cell surface expression of MICL was determined by flow cytometry. MICL siRNA significantly diminishes the cell surface

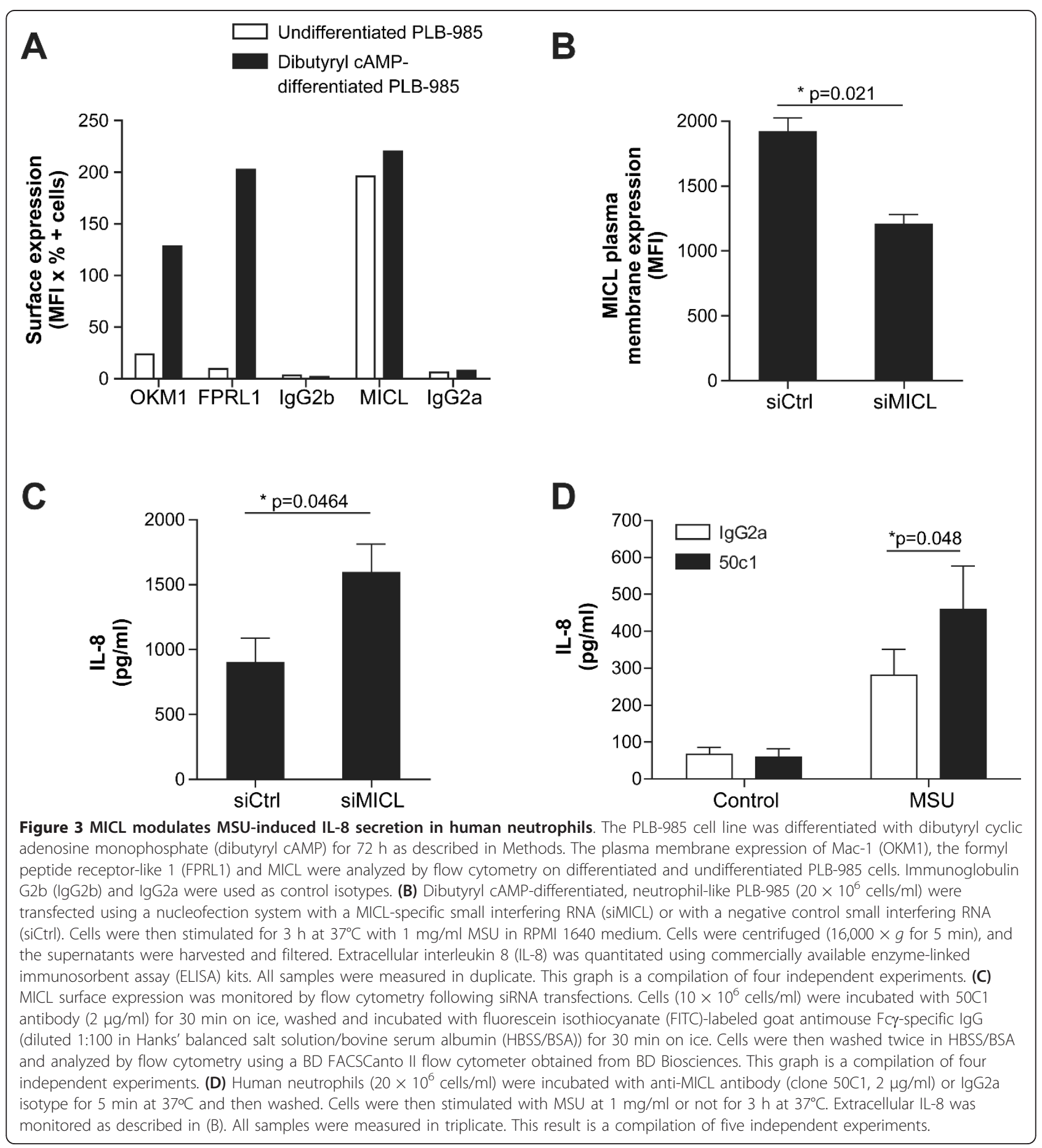


expression of MICL $(P=0.021)$ (Figure 3B). Moreover, the silencing of MICL expression has no effect on the differentiation of PLB-985 cells. The level of expression of Mac-1 and FLPR1 is the same in differentiated cells transfected with the control or MICL siRNA (data not shown).

Having demonstrated that MICL expression can be silenced by MICL-specific siRNA in neutrophil-like PLB985 cells, we next examined how the diminution in MICL expression affects MSU-induced IL-8 production. The amount of IL- 8 measured in the cell-free supernatant of MSU-activated, dibutyryl cAMP-differentiated PLB-985 silenced for MICL expression was significantly superior in comparison to cells transfected with control siRNA (Figure 3C). To confirm this observation in human neutrophils, the internalization of cell surface MICL was induced with the $50 \mathrm{C} 1$ antibody prior to stimulation with MSU, as shown in Figure 1C. Neutrophils incubated with $50 \mathrm{C} 1$ prior to stimulation with MSU produced significantly larger amounts of IL- 8 in the cell-free supernatant (Figure 3D) than in those treated with an isotype antibody (IgG2a). Thus, using two different experimental strategies, we have produced evidence that a reduction in the cell surface expression of MICL potentiates MSU-induced IL-8 production in neutrophils.
Production of IL-1 by monosodium urate crystal-activated human neutrophils is not regulated by myeloid inhibitory C-type lectin-like receptor

Having demonstrated the modulation of the MSUinduced release of IL- 8 by human neutrophils, we next examined the possibility that MICL may regulate the production of IL-1 $\beta$, since this cytokine is reported to play a pivotal role in gout. The MSU-induced synthesis of IL- $1 \beta$ by macrophages, cells that produce this cytokine during the initiation phase of gout, is well-documented. In contrast, the production of IL-1 $\beta$ by MSU-stimulated neutrophils remains poorly characterized. We thus examined the ability of neutrophils to synthesize and release IL-1 $\beta$ in response to MSU. As shown in Figure 4, neutrophils stimulated with MSU do not release detectable amounts of IL-1 $\beta$. This may be explained by the fact that the synthesis of this cytokine is a multistep process involving the synthesis of pro-IL- $1 \beta$ and its subsequent inflammasome-mediated maturation. IL- $1 \beta$ synthesis requires two signals. The first signal is thought to modulate the threshold of the inflammasome and the second, to activate the inflammasome-dependent maturation of pro-IL$1 \beta$ Indeed, the stimulation of neutrophils with MSU after TNF- $\alpha$ priming induces the release of a significant amount of IL-1 $\beta$ in the cell-free supernatant. A similar

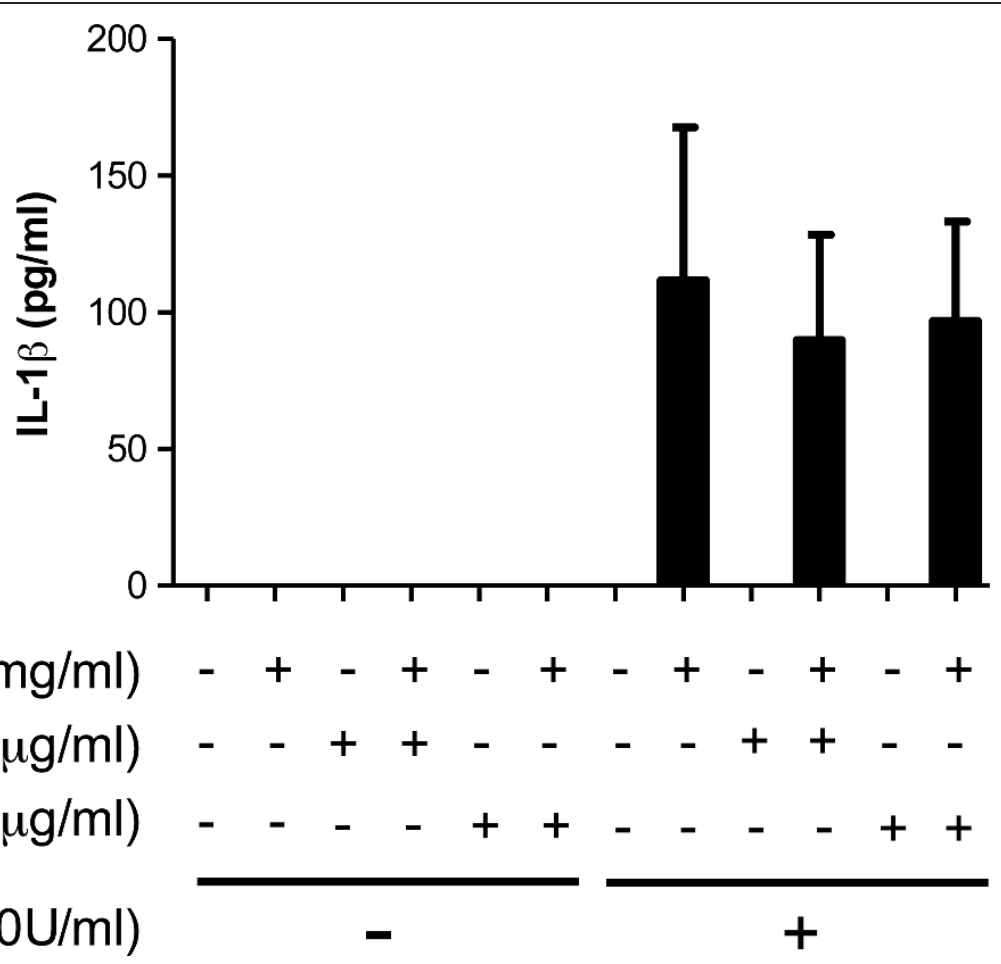

Figure 4 MICL does not modulate MSU-induced IL-1 $\beta$ production in primed, human neutrophils. Resting human neutrophils $\left(20 \times 10^{6}\right.$ cells $/ \mathrm{ml}$ ) or neutrophils incubated with the lgG2a isotype antibody, 50C1, in the presence or absence of TNF- $\alpha$ were stimulated with MSU (1 $\mathrm{mg} / \mathrm{ml}$ ) for $8 \mathrm{~h}$ at $37^{\circ} \mathrm{C}$ and centrifuged, and IL-1 $\beta$ was quantified in the cell-free supernatant by ELISA as described in Methods. All samples were measured in duplicate. This graph is a compilation of four independent experiments. 
amount of IL- $1 \beta$ was measured in the cell-free supernatant of TNF- $\alpha$-primed neutrophils stimulated with MSU after the 50C1-induced internalization of MICL. Together, the above observations indicate that MICL does not regulate the production of IL- $1 \beta$ in neutrophils stimulated with MSU.

\section{Diminution of myeloid inhibitory C-type lectin-like} receptor expression enhances monosodium urate crystalinduced signaling in human neutrophils

Having observed a modulation of IL-8 production by MICL, we next asked whether MICL modulates signaling pathways activated by MSU. We chose to focus on the modulation of MSU-induced tyrosine phosphorylation of intracellular proteins, since ITIM-bearing receptors are notable for regulating early signaling events. Tyrosine phosphorylation of intracellular substrates was visualized by Western blot analysis using an antiphopshotyrosine antibody. The series of bands shown in the blot in Figure 5 represent the distinct tyrosine phosphorylation profile induced in neutrophils by MSU and is consistent with that previously described [21]. A rapid and transient increase in the tyrosine phosphorylation of intracellular substrates was observed within 1 min after stimulation of neutrophils with MSU (Figure 5). Maximum tyrosine phosphorylation was observed approximately 1 to 2 min following MSU stimulation and began to diminish by $5 \mathrm{~min}$. Even though a similar kinetics in the tyrosine phosphorylation of intracellular substrates was observed in neutrophils stimulated with MSU after $50 \mathrm{C} 1$ engagement, the intensity of the tyrosine phosphorylation profile was much higher in these cells than that in neutrophils stimulated with MSU alone. As a control, we show that $50 \mathrm{C} 1$ alone does not induce an intense tyrosine phosphorylation profile of intracellular substrates.

Another early signaling event is the increase in the intracellular levels of cytoplasmic free calcium. We provide evidence that the 50C1-induced diminution of the expression of cell surface MICL significantly enhanced the MSU-induced increase in cytoplasmic free calcium (Figure 6).

Together, the above findings are suggestive of a negative regulatory role for MICL because a decrease in its cell surface expression enhances two of the earliest

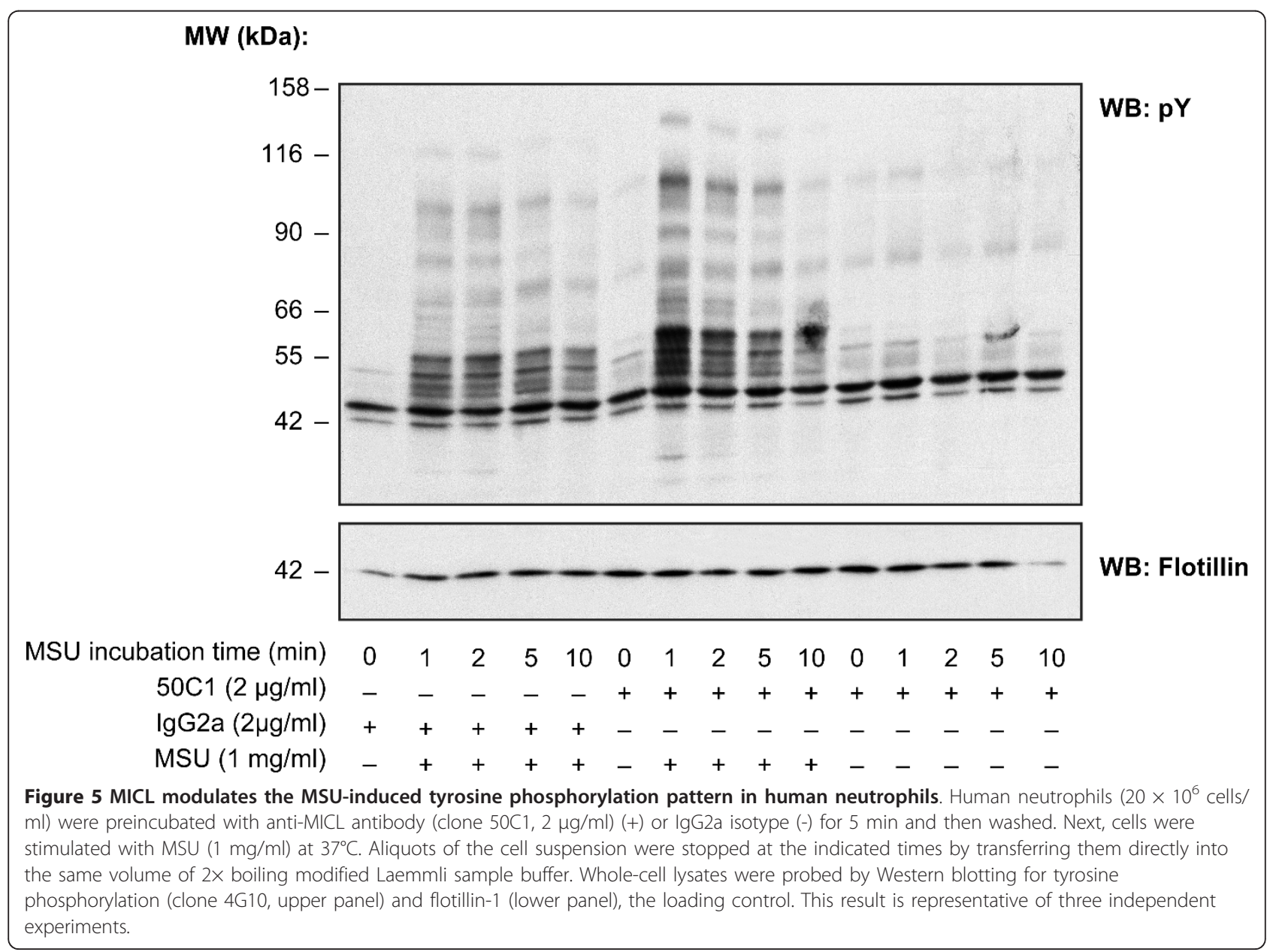




\section{A}

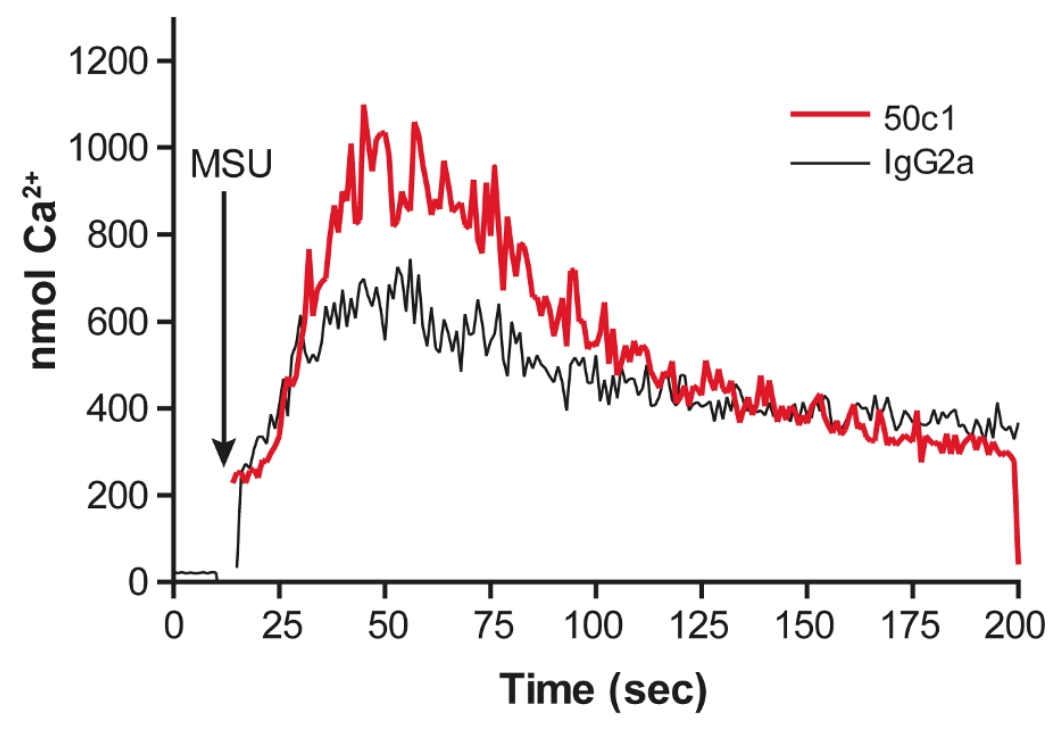

B

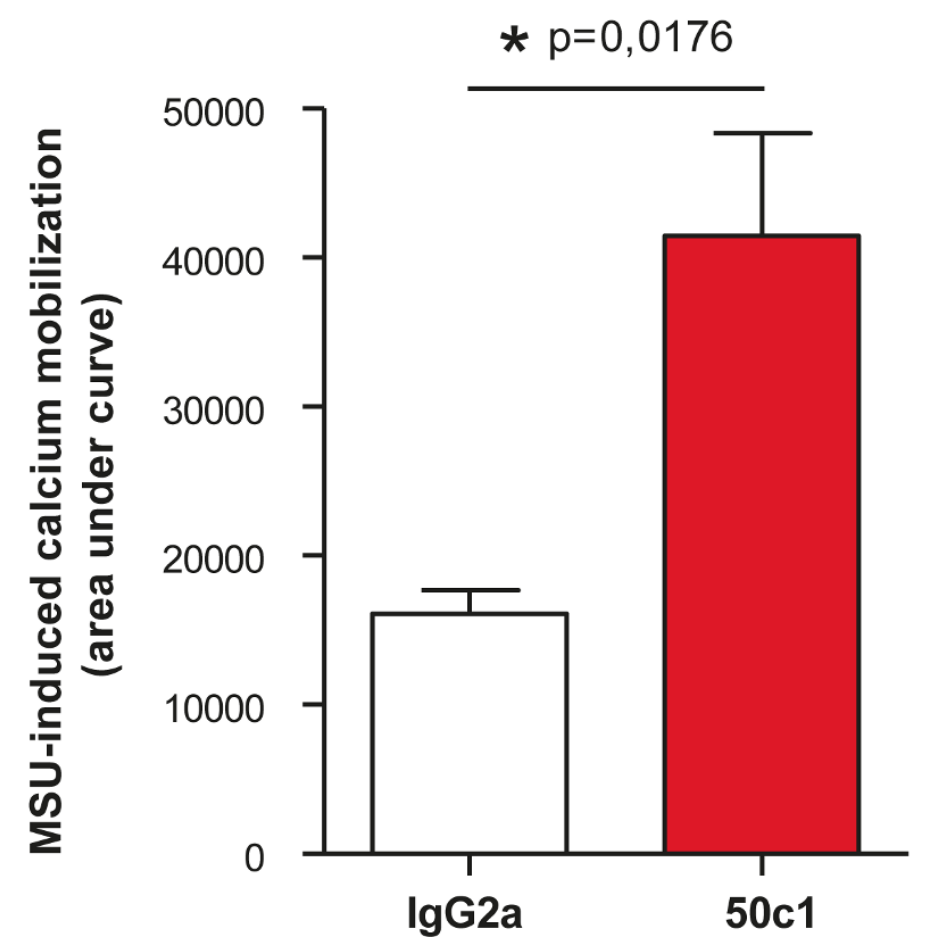

Figure 6 MICL modulates MSU-induced calcium mobilization in human neutrophils. (A) Human neutrophils $\left(10 \times 10^{6}\right.$ cells $\left./ \mathrm{ml}\right)$ were preincubated with Fura-2AM $(1 \mu \mathrm{M})$ for $30 \mathrm{~min}$ at $37^{\circ} \mathrm{C}$. The extracellular probe was removed by washing in HBSS, and the cells were resuspended at $5 \times 10^{6}$ cells $/ \mathrm{ml}$. Anti-MICL antibody (clone $50 \mathrm{C1}, 2 \mu \mathrm{g} / \mathrm{ml}$ ) or lgG2a isotype was added for $5 \mathrm{~min}$. Cells were transferred to a thermostat-controlled $\left(37^{\circ} \mathrm{C}\right)$ cuvette compartment of an SLM 8000 spectrofluorometer. Calcium mobilization was measured following the addition of $1 \mathrm{mg} / \mathrm{ml} \mathrm{MSU}$ at $37^{\circ} \mathrm{C}$. Fluorescence was monitored at an excitation wavelength of $340 \mathrm{~nm}$ and an emission wavelength of $510 \mathrm{~nm}$. The internal calcium concentrations were calculated as described by Grynkiewicz et al. [16]. This result is representative of four independent experiments. 
signaling events in neutrophils upon stimulation with MSU, the tyrosine phosphorylation of intracellular proteins and an increase in intracellular levels of cytoplasmic free calcium.

\section{Colchicine reduces the internalization of myeloid inhibitory C-type lectin-like receptor on human neutrophils}

The modulation by MICL of various neutrophil responses toward MSU led us to hypothesize that anti-inflammatory drugs may dampen inflammation by targeting MICL. Our working hypothesis is that MICL negatively regulates MSU-induced neutrophil responses, since a decrease in its expression enhances the effector functions of neutrophils toward MSU. Because colchicine is very effective in inhibiting a variety of MSU-induced neutrophil effector functions, some of which are modulated by MICL, including calcium mobilization and tyrosine phosphorylation, the effect of this anti-inflammatory drug on the MSU-induced internalization of MICL was examined. The addition of colchicine to resting neutrophils did not affect the expression of MICL as determined by flow cytometry. In contrast, the MSU-induced internalization of MICL was significantly retarded in neutrophils pretreated with colchicine (Figure 7). This effect of colchicine on MICL internalization is specific for the MSU-induced internalization of MICL because colchicine was not able to retard the 50C1-induced loss of MICL cell surface expression. Together, these observations strongly suggest that the anti-inflammatory properties of colchicine may be partially explained by the ability of this drug to preserve the expression of MICL on the surface of human neutrophils.

\section{Colchicine inhibits the production of IL- 8 by monosodium urate crystal-activated human neutrophils}

Colchicine is known to inhibit all the MSU-induced neutrophil responses modulated by MICL. The effect of the alkaloid on the production of IL-8 has not been examined yet, however. Its effect on the production of this cytokine in response to MSU was thus determined. Neutrophils incubated with colchicine produced significantly lower amounts of IL- 8 when activated with MSU than neutrophils stimulated with MSU in the absence of the drug (Figure 8). This finding supports the notion that colchicine inhibits IL-8 production by neutrophils stimulated with MSU in part through MICL because colchicine favors the retention of this inhibitory receptor on the cell surface, precluding the full activation of the neutrophil.

\section{Discussion}

Inhibitory receptors are essential for the maintenance of immune homeostasis by abrogating signaling pathways that lead to cellular activation [5]. Even though inhibitory receptors may contribute to the pathogenesis of inflammatory diseases by virtue of their ability to modulate leukocyte activation, little is known about their roles in disease. This is the first report of the modulation of the expression of an inhibitory receptor by the etiological agent of gout. The activation of human neutrophils with MSU results in the loss of MICL expression. The functional significance of the diminution of MICL expression is an enhancement in the MSU-induced release of IL-8. This finding is of clinical relevance because IL- 8 is a potent neutrophil chemoattractant. The loss of MICL expression may thus be a requisite for the recruitment and/or perpetuation of neutrophil-driven gout flares. Moreover, we also show that an inflammatory drug used to treat gout, colchicine, inhibits the effect of MSU on MICL expression.

Our observation that MSU downregulates MICL expression adds to a growing list of proinflammatory stimuli that diminish the cell surface expression of MICL in neutrophils. MSU is the first damage-associated molecular pattern demonstrated to modulate MICL expression. The biological significance of the negative modulation of MICL expression in neutrophils by proinflammatory stimuli other than MSU (mostly TLR agonists) remains largely unexplored, rendering the interpretation of these results challenging. One report has investigated the functional effect of the diminution of cell surface MICL on cytokine synthesis in monocyte-derived dendritic cells [10]. In that report, Chen et al. demonstrated that a diminution in the expression of cell surface MICL inhibited or augmented cytokine production in a stimulus-dependent manner. In response to LPS, the production of TNF- $\alpha, \mathrm{IL}-12 \mathrm{p} 40$ and IL-12p70 was suppressed upon MICL internalization. In contrast, the production of TNF- $\alpha$, IL-12p40, IL-12p70, IL-6 and IL-10 was enhanced in response to CD40 ligand. Since inhibitory receptors can dampen cellular activation or, in some cases, activate the cells, it remains unclear whether MICL is an inhibitory receptor. We used a siRNA approach to resolve this issue. Our demonstration that the silencing of MICL expression significantly enhances the release of IL- 8 by MSU-activated neutrophils strongly supports the notion that MICL acts as an inhibitory receptor in human neutrophils.

The modulation of IL-8 production by MICL in neutrophils is of relevance to gout. The massive recruitment of neutrophils to the inflamed joint is a pathological hallmark of gout, and this recruitment is reduced in mice deficient in chemokine (C-X-C motif) receptor 2 (CXCR2). It is thus reasonable to propose that the MSU-induced downregulation of MICL expression releases the inhibitory activity of this receptor in neutrophils permitting the activation of the neutrophil by this nonmicrobial agent. Interestingly, MICL does not regulate the MSU-induced production of IL- $1 \beta$. The molecular mechanisms underlying the selective nature of MICL regulation of the production of cytokines by 


\section{A}

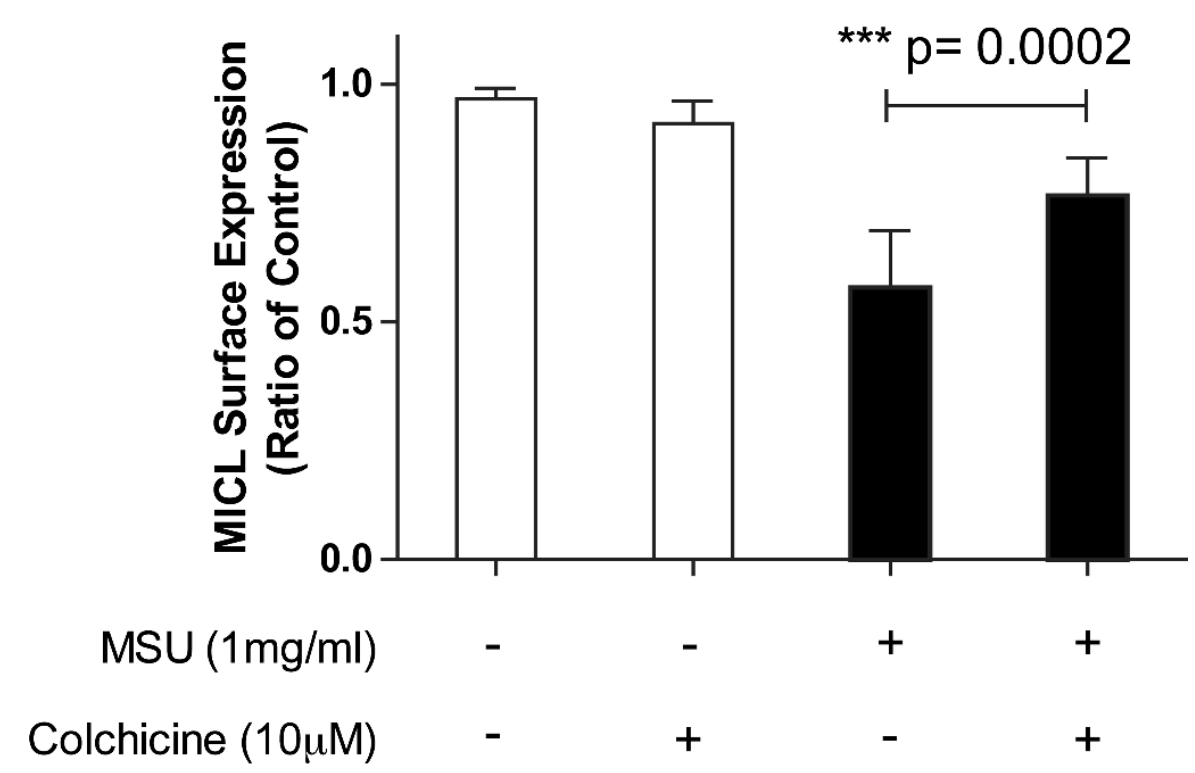

B

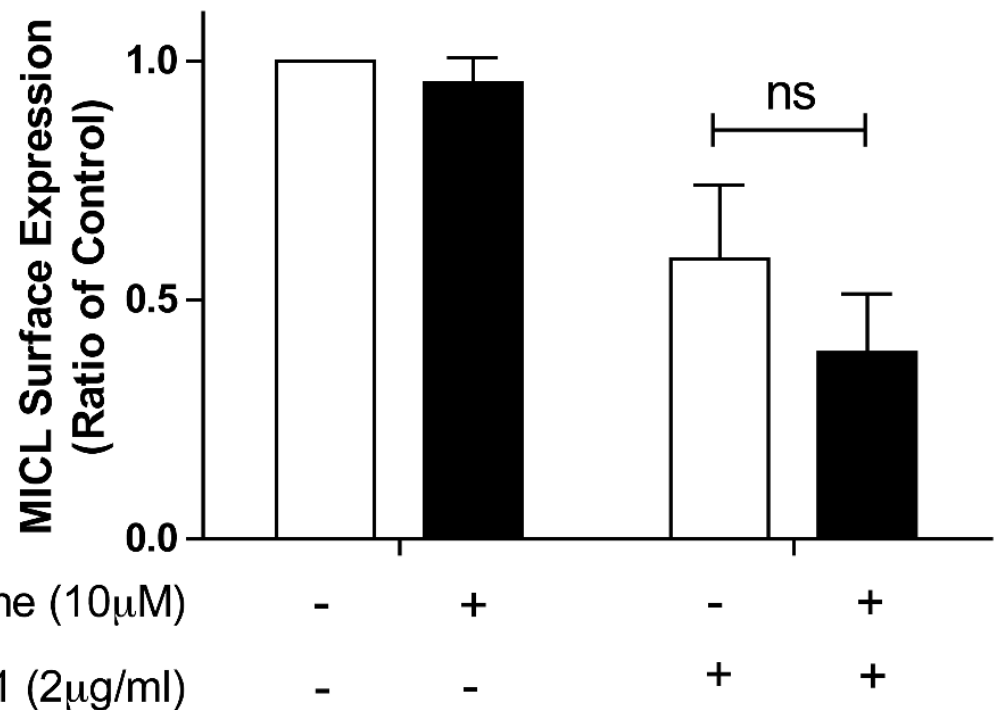

Figure 7 Colchicine inhibits the MSU-induced internalization of MICL in human neutrophils. Freshly isolated human neutrophils were treated with colchicine $(10 \mu \mathrm{M})(+)$ or dimethyl sulfoxide (DMSO) (-) for $30 \mathrm{~min}$ at $37^{\circ} \mathrm{C}$ and then incubated with (A) MSU $(1 \mathrm{mg} / \mathrm{ml})$ for $20 \mathrm{~min}$ at $37^{\circ} \mathrm{C}$ or (B) $50 \mathrm{C} 1 \mathrm{for} 5 \mathrm{~min}$ at $37^{\circ} \mathrm{C}$. The stimulations were terminated by transferring the tubes to an ice bath, followed by centrifugation at $400 \times \mathrm{g}$ for $2 \mathrm{~min}$ at $4{ }^{\circ}$ C. The cell pellets were washed in cold HBSS containing 0.005\% BSA and incubated with (A) $50 \mathrm{C} 1$ for 30 min, followed by incubation with FITClabeled goat antimouse Fc $\gamma$-specific lgG (diluted 1:100 in HBSS/BSA) for 30 min on ice, or (B) FITC-labeled goat anti-mouse Fc $\gamma$-specific lgG (diluted 1:100 in HBSS/BSA) for 30 min on ice. Cells were then washed twice in HBSS/BSA and analyzed by flow cytometry using the FACSCanto II flow cytometer (BD Biosciences). This graph is a compilation of 7 independent experiments in (A) and 3 independent experiments in (B).

MSU-activated neutrophils remain to be identified. Whether MICL modulates the release of other chemotactic factors or cytokines by neutrophils remains to be determined. With regards to the ability of MICL to modulate additional MSU-induced neutrophil responses, we did not observe any modulation of MSU-induced degranulation or 5-lipoxygenase production in human neutrophils subsequent to the antibody-induced internalization of MICL 


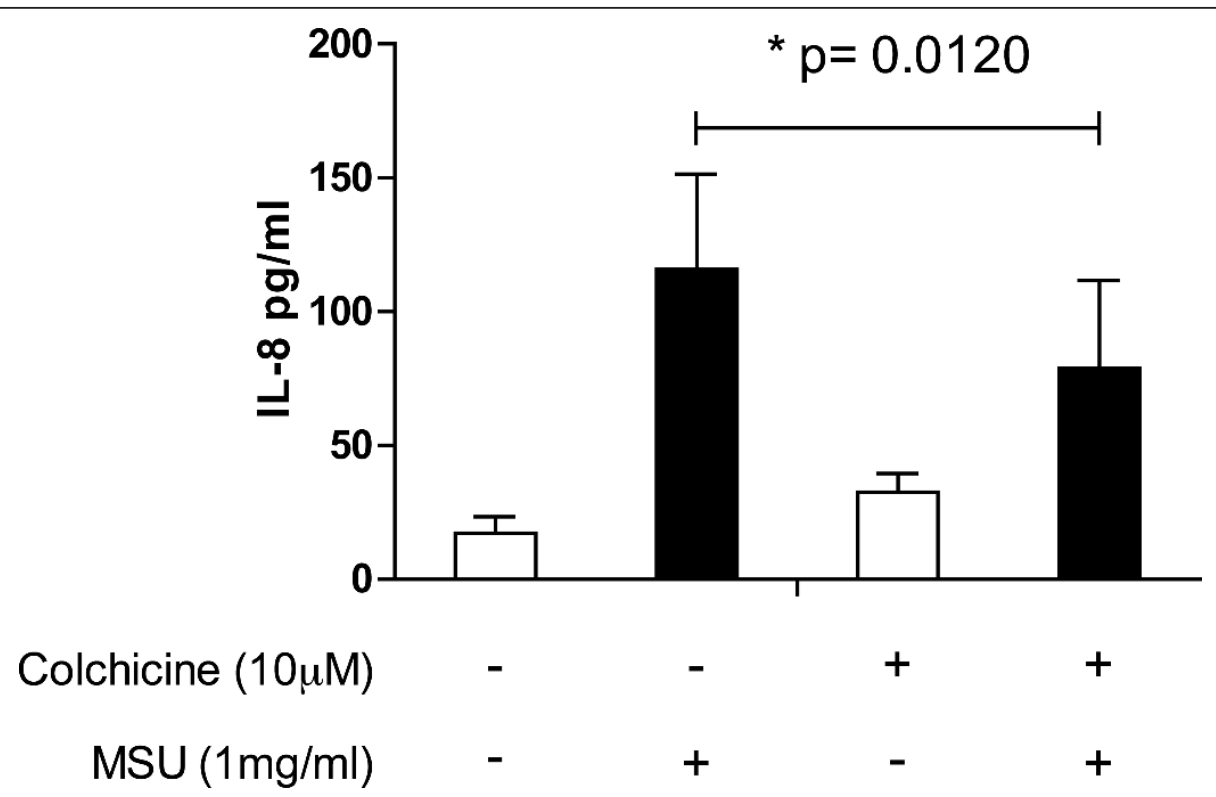

Figure 8 Colchicine modulates MSU-induced IL-8 secretion in human neutrophils. Neutrophils were incubated in colchicine $(10 \mu \mathrm{M})(+)$ or DMSO (-) for $30 \mathrm{~min}$ at $37^{\circ} \mathrm{C}$ prior to adding MSU $(1 \mathrm{mg} / \mathrm{ml})$ or buffer to the neutrophil-colchicine mixture and incubating it for a further $3 \mathrm{~h}$ at $37^{\circ} \mathrm{C}$. The quantity of IL-8 in the supernatant was determined by ELISA. A compilation of the data from three independent experiments is shown $(n=3)$.

(data not shown). These observations suggest that MICL modulates a subset of molecular pathways employed by MSU to activate human neutrophils.

At the molecular level, we show that MICL modulates early MSU-induced signaling events in neutrophils. The stimulation of neutrophils with MSU induced the loss of cell surface MICL leading to the enhancement of the MSU-induced increase in the concentration of intracellular calcium and tyrosine phosphorylation of intracellular substrates. These observations corroborate the observed enhancement in MSU-induced IL-8 production upon the downregulation of MICL expression. Both MSU-induced tyrosine phosphorylation and IL- 8 production depend on the activation of Src kinases in neutrophils. The inhibition by MICL of MSU-induced early signaling events is consistent with the known mode of action of inhibitory receptors and is strongly suggestive that MICL may regulate several MSU-induced neutrophil effector functions driven by downstream signaling events.

Neutrophils pretreated with colchicine internalize significantly less cell surface MICL in the presence of MSU. This observation provides additional evidence for the ability of MICL to negatively regulate the MSUinduced activation of neutrophils. We propose that colchicine preserves the cell surface expression and consequently the inhibitory activity of MICL, shifting the balance between pro- and anti-inflammatory signals toward the latter. It thus follows that MSU may induce tyrosine phosphorylation of intracellular substrates and the mobilization of intracellular calcium in part by internalizing MICL, because these neutrophil responses are enhanced subsequent to the antibody-induced internalization of MICL and inhibited by colchicine. Regarding the MSU-induced secretion of IL-8, the ability of colchicine to inhibit this neutrophil response to MSU remains unexplored. We thus investigated the effect of colchicine on the production of this cytokine in response to MSU. Colchicine downregulates the MSUinduced release of IL-8 in human neutrophils (Figure 8). Together, these observations strongly suggest that MICL regulates very early signaling events involving $\mathrm{Src}$ kinases because MSU-induced tyrosine phosphorylation of intracellular substrates, as well as the increases in the concentrations of free cytosolic calcium and the production of IL-8, are all Src tyrosine kinase-dependent events. MICL is the first inhibitory pathway identified that could partly explain the antiphlogistic activity of colchicine. Since colchicine destabilizes microtubules by binding $\alpha$ and $\beta$ monomers of tubulin, it is not unreasonable to suggest that MICL interacts directly or indirectly with the microtubule network.

A limitation of our experimental approach is that the internalization of MICL was induced prior to MSU stimulation to investigate the effect of MICL on MSUinduced responses. Although this approach is widely used to investigate inhibitory receptors whose ligands remain unidentified, it remains to be determined whether cells expressing a mutant form of MICL that is resistant to MSU-induced internalization and/or degradation respond more weakly to MSU. 
As mentioned above, MSU are the first damageassociated molecular pattern shown to modulate MICL expression and consequentially its function. The regulation of MICL expression by damage-associated molecular patterns may differ from that of pathogen-associated molecular patterns and other proinflammatory stimuli. Indeed, MSU is the only stimulus that we studied that modulates MICL expression in resting neutrophils. Moreover, studies that previously published the diminution of cell surface MICL by stimuli other than damage-associated molecular patterns were performed on primed neutrophils. We show that in resting neutrophils, however, MICL expression is not modulated by proinflammatory stimuli that are not damage-associated molecular patterns. Together, these observations indicate that neutrophils have to receive two stimuli and/or signals prior to mobilizing cell-surface MICL when activated with non-damage-associated molecular pattern stimuli. In contrast, damage-associated molecular patterns seem to be able to override the necessity of a primary signal (neutrophil priming) and affect MICL expression directly.

\section{Conclusion}

Our findings strongly suggest that MICL may play a pathogenic role in gout by being one of the targets of MSU. We propose that MSU downregulate the inhibitory activity of MICL by diminishing its expression, resulting in the full activation of human neutrophils. In contrast, colchicine has the opposite effect on the cell surface expression of MICL. MICL is thus a potential therapeutic target for gout. Further characterization of the role of MICL in MSU-induced neutrophil activation and the molecular events driving MICL function is necessary to shed light on the pathogenic role of MICL in gout and its potential as a drug target. Since neutrophils are the principal players in the inflammatory flares typical of gout, it is not unreasonable to suggest that MICL may also play a similar pathogenic role in other chronic diseases characterized by recurrent, neutrophil-driven inflammatory episodes, such as rheumatoid arthritis. It is thus of interest to gain further insight into the potential role of MICL in the effector phase of these chronic inflammatory diseases.

\section{Abbreviations \\ CTLD: C-type lectin-like domain; dibutyryl CAMP: N ${ }^{6}: 2^{\prime}-\mathrm{O}-$-dibutyryladenosine- 3':5'-cyclic monophosphate sodium salt; ITIM: immunoreceptor tyrosine- based inhibitory motifs; MICL: myeloid inhibitory C-type lectin-like receptor; MSU: monosodium urate crystals; siCtrl: control siRNA; siMICL: MICL-specific SiRNA}

\section{Competing interests}

The authors declare that they have no competing interests.

\section{Authors' contributions}

$V G, L M, J M L$ and $H G$ performed the experiments and analyzed and interpreted the data. LM also participated in the writing of the manuscript and revised it for intellectual content. MJFG conceived the project, participated in its design and coordination, and drafted and revised the manuscript. MHL, IC, PHN and PT contributed to the design of the project and revised the manuscript critically for important intellectual content. All authors read and approved the final manuscript.

\section{Acknowledgements}

The authors thank Dr Alexandre Brunet for expert technical assistance in flow cytometry analysis. We also thank Myriam Vaillancourt for her technical assistance in IL-8 ELISA analysis. This research was funded by operating funds awarded to MJGF by the Canadian Arthritis Network (CAN), the Natural Sciences and Engineering Research Council of Canada (NSERC) and the Crohn's and Colitis Foundation of Canada (CCFC). LM is a recipient of the Canadian Arthritis Network post-doctoral award and VG received a Ph.D. scholarship from Fonds de recherche Québec-Santé and the CCFC. MJGF is a recipient of the Arthritis Society Investigator Award.

\section{Authors' details}

'Department of Microbiology, Infectious Diseases, and Immunology, Faculty of Medicine, Laval University, Centre for Research in Immunology and Rheumatology, Research Centre CHUQ-CHUL, Bloc T1-49, 2705 boulevard Laurier, Quebec, QC, GIV 4G2, Canada. ${ }^{2}$ Walter and Eliza Hall Institute of Medical Research, 1G Royal Parade, Parkville, VIC 3050, Australia.

Received: 6 October 2012 Revised: 18 March 2013

Accepted: 9 July 2013 Published: 9 July 2013

\section{References}

1. Martinon F: Mechanisms of uric acid crystal-mediated autoinflammation. Immunol Rev 2010, 233:218-232.

2. Weaver AL: Epidemiology of gout. Cleve Clin J Med 2008, 75(Suppl 5): S9-S12.

3. Busso N, So A: Mechanisms of inflammation in gout. Arthritis Res Ther 2010, 12:206.

4. Popa-Nita O, Naccache PH: Crystal-induced neutrophil activation. Immunol Cell Biol 2010, 88:32-40.

5. Daëron $M$, Jaeger $S$, Du Pasquier L, Vivier E: Immunoreceptor tyrosinebased inhibition motifs: a quest in the past and future. Immunol Rev 2008, 224:11-43.

6. Pyz E, Marshall AS, Gordon S, Brown GD: C-type lectin-like receptors on myeloid cells. Ann Med 2006, 38:242-251.

7. Steevels TA, Meyaard L: Immune inhibitory receptors: essential regulators of phagocyte function. Eur J Immunol 2011, 41:575-587.

8. Marshall AS, Willment JA, Lin HH, Williams DL, Gordon S, Brown GD: Identification and characterization of a novel human myeloid inhibitory C-type lectin-like receptor (MICL) that is predominantly expressed on granulocytes and monocytes. J Biol Chem 2004, 279:14792-14802.

9. Marshall AS, Willment JA, Pyz E, Dennehy KM, Reid DM, Dri P, Gordon S, Wong SY, Brown GD: Human MICL (CLEC12A) is differentially glycosylated and is down-regulated following cellular activation. Eur J Immunol 2006, 36:2159-2169.

10. Chen CH, Floyd H, Olson NE, Magaletti D, Li C, Draves K, Clark EA: Dendritic-cell-associated C-type lectin 2 (DCAL-2) alters dendritic-cell maturation and cytokine production. Blood 2006, 107:1459-1467.

11. Han Y, Zhang M, Li N, Chen T, Zhang Y, Wan T, Cao X: KLRL1, a novel killer cell lectinlike receptor, inhibits natural killer cell cytotoxicity. Blood 2004, 104:2858-2866.

12. Bakker $A B$, van den Oudenrijn $S$, Bakker $A Q$, Feller $N$, van Meijer $M$, Bia JA, Jongeneelen MA, Visser TJ, Bijl N, Geuijen CA, Marissen WE, Radosevic K, Throsby M, Schuurhuis GJ, Ossenkoppele GJ, de Kruif J, Goudsmit J, Kruisbeek AM: C-type lectin-like molecule-1: a novel myeloid cell surface marker associated with acute myeloid leukemia. Cancer Res 2004, 64:8443-8450.

13. Lahoud MH, Proietto Al, Ahmet F, Kitsoulis S, Eidsmo L, Wu L, Sathe P, Pietersz S, Chang HW, Walker ID, Maraskovsky E, Braley H, Lew AM, Wright MD, Heath WR, Shortman K, Caminschi I: The C-type lectin Clec12A present on mouse and human dendritic cells can serve as a target for antigen delivery and enhancement of antibody responses. J Immunol 2009, 182:7587-7594.

14. Naccache PH, Grimard M, Roberge CJ, Gilbert C, Lussier A, de Médicis R, Poubelle PE: Crystal-induced neutrophil activation. I. Initiation and 
modulation of calcium mobilization and superoxide production by microcrystals. Arthritis Rheum 1991, 34:333-342.

15. Fernandes MJG, Lachance G, Paré G, Rollet-Labelle E, Naccache PH: Signaling through CD16b in human neutrophils involves the Tec family of tyrosine kinases. J Leukoc Biol 2005, 78:524-532.

16. Grynkiewicz G, Poenie M, Tsien RY: A new generation of $\mathrm{Ca}^{2+}$ indicators with greatly improved fluorescence properties. J Biol Chem 1985, 260:3440-3450

17. Marois L, Vaillancourt M, Marois S, Proulx S, Paré G, Rollet-Labelle E, Naccache PH: The ubiquitin ligase c-Cbl down-regulates FcyRlla activation in human neutrophils. J Immunol 2009, 182:2374-2384

18. Marois L, Vaillancourt M, Paré G, Gagné V, Fernandes MJG, Rollet-Labelle E, Naccache PH: CIN85 modulates the down-regulation of FcyRlla expression and function by $\mathrm{c}-\mathrm{Cbl}$ in a PKC-dependent manner in human neutrophils. J Biol Chem 2011, 286:15073-15084.

19. Popa-Nita O, Marois L, Paré G, Naccache PH: Crystal-induced neutrophil activation: X. Proinflammatory role of the tyrosine kinase Tec. Arthritis Rheum 2008, 58:1866-1876.

20. Pivot-Pajot C, Chouinard FC, El Azreq MA, Harbour D, Bourgoin SG: Characterisation of degranulation and phagocytic capacity of a human neutrophilic cellular model, PLB-985 cells. Immunobiology 2010, 215:38-52.

21. Roberge CJ, Gaudry M, de Médicis R, Lussier A, Poubelle PE, Naccache PH: Crystal-induced neutrophil activation. IV. Specific inhibition of tyrosine phosphorylation by colchicine. J Clin Invest 1993, 92:1722-1729.

doi:10.1186/ar4250

Cite this article as: Gagné et al:: Modulation of monosodium urate crystal-induced responses in neutrophils by the myeloid inhibitory C-type lectin-like receptor: potential therapeutic implications. Arthritis Research \& Therapy 2013 15:R73.

\section{Submit your next manuscript to BioMed Central} and take full advantage of:

- Convenient online submission

- Thorough peer review

- No space constraints or color figure charges

- Immediate publication on acceptance

- Inclusion in PubMed, CAS, Scopus and Google Scholar

- Research which is freely available for redistribution

Submit your manuscript at www.biomedcentral.com/submit 